\title{
SPATIAL VARIATION OF WITHIN-DAY AND BETWEEN-DAY CHLOROPHYLL A DYNAMICS DURING SUMMER IN GUANTING RESERVOIR, BEIJING, CHINA
}

\author{
JIANG, W. W. ${ }^{1}-$ YU, J. S. $.^{*}-$ LI, Z. J. ${ }^{1}-$ NAKAMURA, T. ${ }^{2}-$ YU, F. Q. ${ }^{1}-$ ZHANG, J. Y. ${ }^{3}$ \\ ${ }^{1}$ College of Water Sciences, Beijing Normal University/Key Laboratory of Urban Hydrological \\ Cycle and Sponge City Technology/Digital Watershed Laboratory, Beijing 100875, China \\ ${ }^{2}$ Department of Global Engineering for Development, Environment and Society, Tokyo Institute \\ of Technology, Yokohama 226-8502, Japan \\ ${ }^{3}$ Shijiazhuang Hydrology and Water Resources Survey Bureau of Hebei Province, \\ Shijiazhuang 050051, China \\ *Corresponding author \\ e-mail: yujingshanbnu@163.com; phone: +86-188-1091-5172; fax: +86-010-6225-1121
}

(Received $11^{\text {th }}$ Jan 2019; accepted $8^{\text {th }}$ Mar 2019)

\begin{abstract}
Recognizing intra- and inter-daily dynamics of chlorophyll a (Chl-a) and its related environmental variables on consecutive days is essential to assessing and managing water quality and eutrophication. In this study, the Chl-a concentration, nutrients, water temperature and meteorological factors in Guanting Reservoir in Beijing were collected at six sampling times during summer. The Chl-a concentration generally decreased from May to September. At both test times, thermal stratification and mixing in the water column controlled temporal and vertical variations in the maximum Chl-a concentration layer. The position of the maximum Chl-a concentration layer between days generally followed that of the thermocline. Daily stratifications were temporary and downwelling variations in the maximum Chl-a concentration layer were wind driven; therefore, the vertical distribution of Chl-a was homogenized at night. Surface Chl-a concentrations increased at night and decreased during the day, except on rainy days. Principal component analysis and Pearson's correlations indicated that daily average and raw surface Chl-a concentrations generally changed as a negative function of air temperature, solar radiation, wind speed and water temperature. However, when a 5-hour time lag was considered, the relationship between surface $\mathrm{Chl}-\mathrm{a}$ concentration, all meteorological factors and water temperature became significantly positive.
\end{abstract}

Keywords: eutrophication, reservoir stratification, phytoplankton occurrence, meteorological factors, short-term distribution

\section{Introduction}

Chlorophyll a (Chl-a) is an important indicator of phytoplankton biomass that is of significance to analysis of the magnitude and extent of trophic state in lakes and reservoirs (Felip and Catalan, 2000; Bresciani et al., 2013; Wu et al., 2014). To adequately recognize the response of Chl-a to ecological changes in phytoplankton and its life cycle, spatial and temporal phytoplankton distributions have been analyzed and documented by many researchers (Pérez-Ruzafa et al., 2005; Wu and Kong, 2009; Zhou et al., 2016; Li et al., 2017). It is generally known that the dynamics of phytoplankton growth and algal blooms are controlled by combined environmental factors such as hydrodynamic conditions (wind speed and direction, bottom topography, stratification pattern, water velocity and discharge) (Cao et al., 2006; Cardoso and Motta-Marques, 2009; Li et al., 2017), nutrients (total nitrogen, total phosphorus, and TN:TP ratio) (Wang et al., 2008; Wu et al., 2014), physical variables (air temperature, light, water 
temperature and turbidity) (Serra et al., 2007), characteristics of phytoplankton (species, size and buoyancy) (Lopes et al., 2005) and hydraulic management (León et al., 2016). Of these factors, nutrient supply and light are generally considered the primary variables limiting phytoplankton growth (Phlips et al., 1995; Becker et al., 2010; Zhou et al., 2016). However, the most influential or primary environmental factor controlling phytoplankton growth differs according to spatial and temporal scale and trophic state of the studied systems. León et al. (2016) demonstrated that stratification pattern and residence time are of great importance to reservoir trophic state and vertical distribution of Chl-a between seasons. Moreover, water temperature has been shown to be a more important factor in mesotrophic lakes than oligotrophic and eutrophic lakes (Rigosi et al., 2016). In shallow lakes, the negative effects of increasing wind on phytoplankton growth can be crucial because it leads to increased resuspension (Cardoso and MottaMarques, 2009).

Investigating the phytoplankton dynamics in the short term is of great importance to recognizing the mechanism of phytoplankton growth for long term variations (Bresciani et al., 2013). It is well known that phytoplankton is characterized by obvious circadian variations (Neveux et al., 2003), which depend directly on their response to diurnal available solar radiation during the day (Wu and Kong, 2009). Serra et al. (2007) demonstrated that most processes involved in phytoplankton growth occur for less than 1 week. When investigating phytoplankton at short time intervals, previous studies have mainly focused on phytoplankton species and community structure (Lopes et al., 2005), the effects of stratification and wind on vertical mixing and advection movement of phytoplankton (Antenucci and Imerito, 2000; Marcé et al., 2006; León et al., 2016) and the relationship between Chl-a and environmental variables (Felip and Catalan, 2000; Cyr, 2017), as well as the time lag of Chl-a (Pérez-Ruzafa et al., 2005; Bresciani et al., 2013). For instance, León et al. (2016) reported that stratification changes the vertical profile of residence time, which is negatively correlated with phytoplankton biomass. Wind driven phytoplankton vertical downwelling (Cardoso and Motta-Marques, 2009) and night-time convective cooling would homogenize the vertical distribution of phytoplankton (Serra et al., 2007). Moreover, the interannual data ln (Chl-a) illustrated a positive correlation with average air temperature (Zhou et al., 2016); however, when the short-term data set was evaluated, Chl-a concentration was negatively correlated with average air temperature (Bresciani et al., 2013). These discrepancies in the association of Chl-a concentration and other environmental variables may be caused by differences in the time scales of the investigated datasets.

Before 1997, Guanting Reservoir was a source of drinking, industrial, and agricultural water in Beijing, China (Dai et al., 2008). However, the reservoir is now in a eutrophic state (He et al., 2008), and the concentration of phosphorus in the reservoir is much higher than the normal criterion for drinking water (Cui et al., 2005). Additionally, the trophic state index is higher than 50, which is based on total nitrogen (TN) and total phosphorus (TP) (He et al., 2011). Previous studies conducted in Guanting Reservoir have investigated the trophic state of its water body based on monitoring of sediment P-decomposing bacteria (Cui et al., 2005), water quality (He et al., 2008), cyanobacteria and their toxins (Dai et al., 2008), and microcystis water blooms (Chen et al., 2011), as well as water quality modeling (He et al., 2011). However, knowledge regarding short-term variations in phytoplankton distribution in the reservoir is relatively scarce and the relationship between $\mathrm{Chl}-\mathrm{a}$ and other environmental variables in unclear. Therefore, continuous and multiple measurements 
taken in the short term are needed to acquire a better understanding of the variability in Chl-a concentrations. Fluorescence method may not measure all phytoplankton activity (Bresciani et al., 2013). Distinct phytoplankton groups can be measured by fluorometric probes and the phytoplankton groups are summarized in Beutler et al. (2002). However, it has been used as a reliable alternative to the in situ and in vivo study of phytoplankton distribution and activity (Serra et al., 2007; Wu and Kong, 2009). According to a previous study, algal blooms in Guanting Reservoir began in late May and disappeared in early October (He et al., 2011). In the present study, samples were collected over six periods ranging from 2 to 3 days from late May to early September to detect vertical and surface variations in Chl-a concentration.

The specific objectives of this study were (1) to investigate vertical and surface distributions and diurnal variations in Chl-a, (2) to relate this variability of Chl-a to stratification patterns, nutrients and wind during the study period and (3) to correlate Chl-a data with water temperature and meteorological data during the study period.

\section{Materials and methods}

\section{Reservoir and site description}

This study was conducted in Guanting Reservoir, which is located in northwest Beijing (Fig. 1). The watershed area and storage capacity of the reservoir are approximately $4.34 \times 10^{4} \mathrm{~km}^{2}$ and $2.19 \times 10^{10} \mathrm{~m}^{3}$, respectively. In the past 30 years, Guanting Reservoir has played an important role in local development through electricity generation, fishing, tourism, and other uses. More importantly, it has been a source of drinking, industrial, and agricultural water in Beijing. However, the rapid development of upriver and surrounding areas has led to serious pollution. As a result, Guanting Reservoir has not been used as a drinking water source since 1997 (Dai et al., 2008). The government made great efforts to restore the reservoir in 2006 and its water quality recovered to Level III according to the Environmental Quality Standards for Surface Water (He et al., 2008). Thus, Guanting Reservoir has the potential to once again be a drinking water source for Beijing.

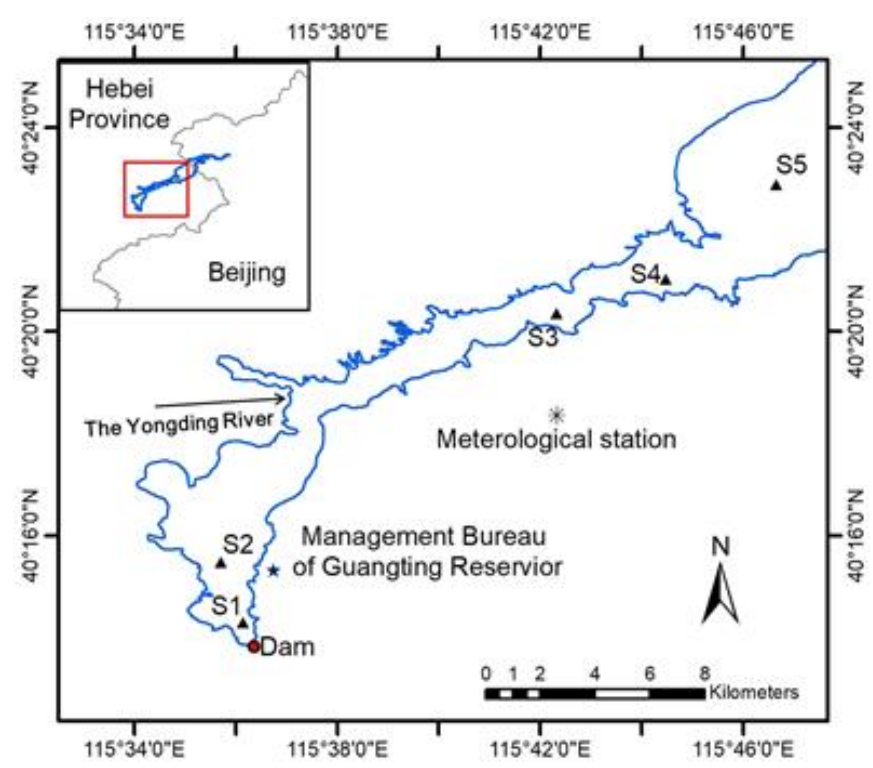

Figure 1. Map of sampling locations in Guanting Reservoir 
Measurements of spatial and seasonal variations of Chl-a has been carried out in Guanting Reservoir in 2014 (Sun et al., 2015), which shows the algal blooms appeared in the area near the dam during summer in Guanting Reservoir (Figs. 1 and 2). Consequently, this present study extends the work of Sun et al. (2015) by investigating short-term variability of Chl-a concentrations in the area near the dam during summer. The average hydraulic residence time of Guanting reservoir is 467 days. A field sample site located in a relatively closed and calm area with maximum Chl-a concentration of 2014 that was suitable for in-situ testing was selected to investigate short-term vertical variations in Chl-a concentration (S1 in Fig. 2). The topography contour map of Guanting reservoir can be seen in He et al. (2011). The outlet discharge varies by time of week and draws off water at a depth of $8 \mathrm{~m}$. The site was located near the dam in the deepest portion of the entire reservoir. The average water depth for each test time was about $11 \mathrm{~m}$, which was ideal for investigation of the vertical dynamics of Chl-a concentration.

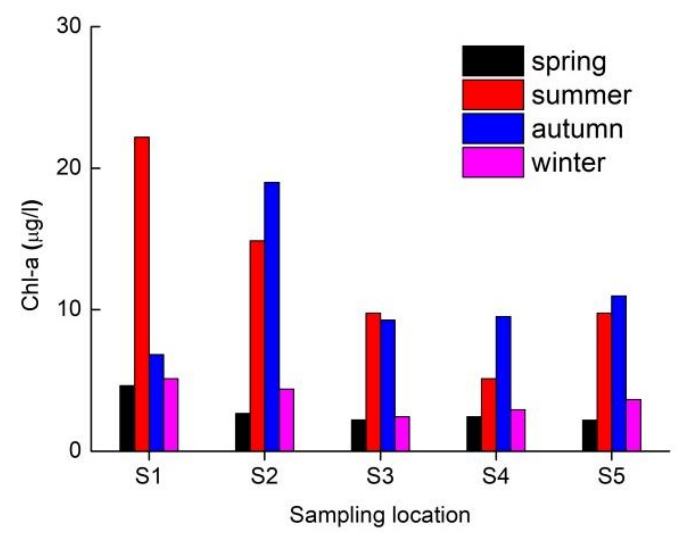

Figure 2. Spatial and seasonal variability of Chl-a in Guanting Reservoir. (Adapted from Sun et al., 2015)

\section{Sampling and analysis}

A total of six investigations including four rounds of vertical sampling and two rounds of surface sampling were conducted from 29 May to 9 Sep, 2015 (Figs. 3 and 4). On the vertical sampling days, the Chl-a concentration was obtained based on the fluorescent attributes of Chl-a concentration using an INFINITY water quality sensor (Onset, USA). The water temperature at each water depth was measured using a HOBO U20 recorder (Onset, USA), which had a measurement accuracy of $\pm 0.21{ }^{\circ} \mathrm{C}$. A selfmade lifting device was employed to move the aforementioned devices throughout each day (Fig. 5), six times during daytime $(8: 00 \mathrm{~h}, 10: 00 \mathrm{~h}, 12: 00 \mathrm{~h}, 14: 00 \mathrm{~h}, 16: 00 \mathrm{~h}$ and 18:00 h) and four times during night $(21: 00 \mathrm{~h}, 0: 00 \mathrm{~h}, 3: 00 \mathrm{~h}$ and 6:00 h). Chl-a concentration and water temperature data were vertically collected for each lifting time at 1-min intervals. Throughout all sampling times, a global positioning system (GPS, HOLUXGM-101, China) was used to precisely ensure the sampling location. It should be noted that few vertical samples were obtained from the water column during the last test period (Fig. 3d). This occurred because of a lack of power for the self-made lifting device from 6:00 h on 8/September, which caused it to stop lifting; therefore, only surface samples were collected from this point to the end of the study period. Water quality parameters including $\mathrm{DO}, \mathrm{pH}$ and turbidity were determined in situ using a 
Hydrolab Multi-parameter water quality sensor (Hach, USA). Based on He et al. (2011), the thermocline appeared at a depth of $4 \mathrm{~m}$ of Guanting reservoir during summer. Representative water samples $(1500 \mathrm{ml})$ were collected from a depth of $2 \mathrm{~m}$ at noon during each test period and transported to the laboratory, where they were analyzed for total nitrogen (TN), ammonium $\left(\mathrm{NH}_{4}\right)$, total phosphorus (TP) and chemical oxygen demand $\left(\mathrm{COD}_{\mathrm{Mn}}\right)$ according to the American Public Health Association (APHA, 1998). Furthermore, the daily discharge at the dam was obtained from Beijing Guanting Reservoir Management Bureau. A small meteorological sensor (JLC-QTF, China) was installed on shore (Fig. 1) and meteorological factors including air temperature, solar radiation, wind speed, wind direction and precipitation were recorded at 5-min intervals.
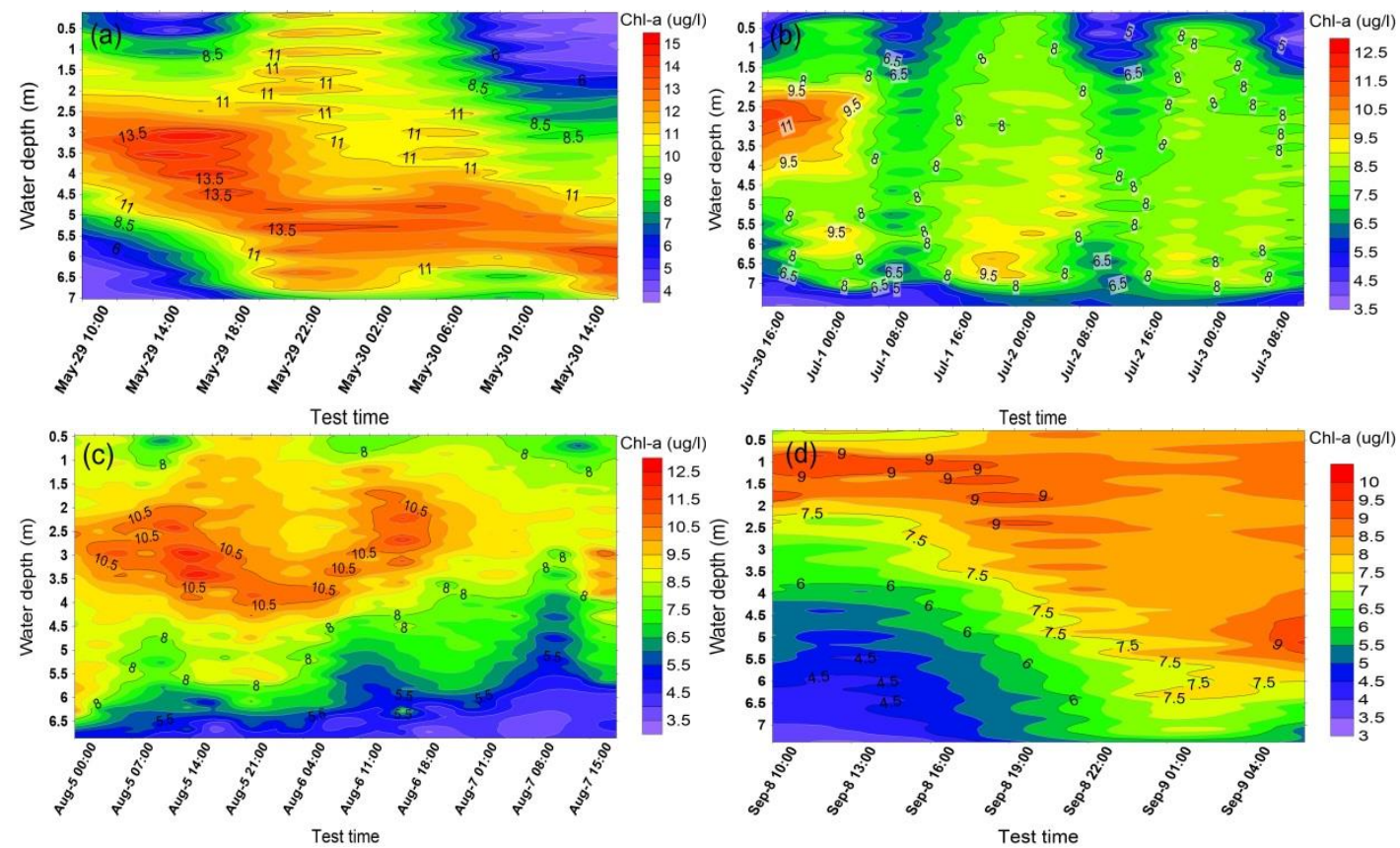

Figure 3. Interpolated contour maps of vertical Chl-a distributions for each test time

\section{Data analysis}

To detect short-term variations in Chl-a concentration and water temperature during each test time, isocline interpolation maps were prepared using the Surfer 8.0 package of Windows (Lopes et al., 2005). Additionally, SPSS 19.0 for Windows was used to conduct Pearson's correlations between Chl-a concentration and environmental variables (Wu et al., 2014), while principal component analysis (PCA) was performed using the CANOCO 4.5 software (Bresciani et al., 2013). It should be noted that PCA could not be applied to the water quality data because there were too few samples; therefore, the average daily Chl-a was set as an environment variable, and average daily values for each variable were used to test its relationship with water temperature, turbidity, discharge and meteorological data.

\section{Results}

Meteorological data during each test time is shown in Figure 6. The range of air temperature and wind speed (Table 1) of this study year is generally consistent with 
meteorological factors reported in previous study (Xie and Xu, 2014). Generally, lower levels of solar radiation were recorded in May and July and the wind speed was mostly below $0.5 \mathrm{~m} / \mathrm{s}$ at night (Fig. $6 a$ and $b$ ). Because of the effects of cloudiness, solar radiation was largely half sinusoidal (Fig. $6 c$ and $f$ ). However, the wind speed was clearly greater in May and July than August and September (Fig. $6 d$ and $e$ ). Moreover, relatively high wind speeds ( $>5 \mathrm{~m} / \mathrm{s}$ ) were observed on 30/May and $1 / \mathrm{July}$. Specifically, there was no obviously predominant wind direction in August and September, while the predominant wind direction and frequency were northwest and north (27\% and 30\%) on $30 /$ May and $1 / \mathrm{July}$, respectively (Table 1). The study period was rain free except for an event on 1/Jul from 18:00 $\mathrm{h}$ to 23:00 $\mathrm{h}$ and on 9/September from 8:00 to 22:00, during which time the daily precipitation was $16.5 \mathrm{~mm}$ and $5.4 \mathrm{~mm}$, respectively.
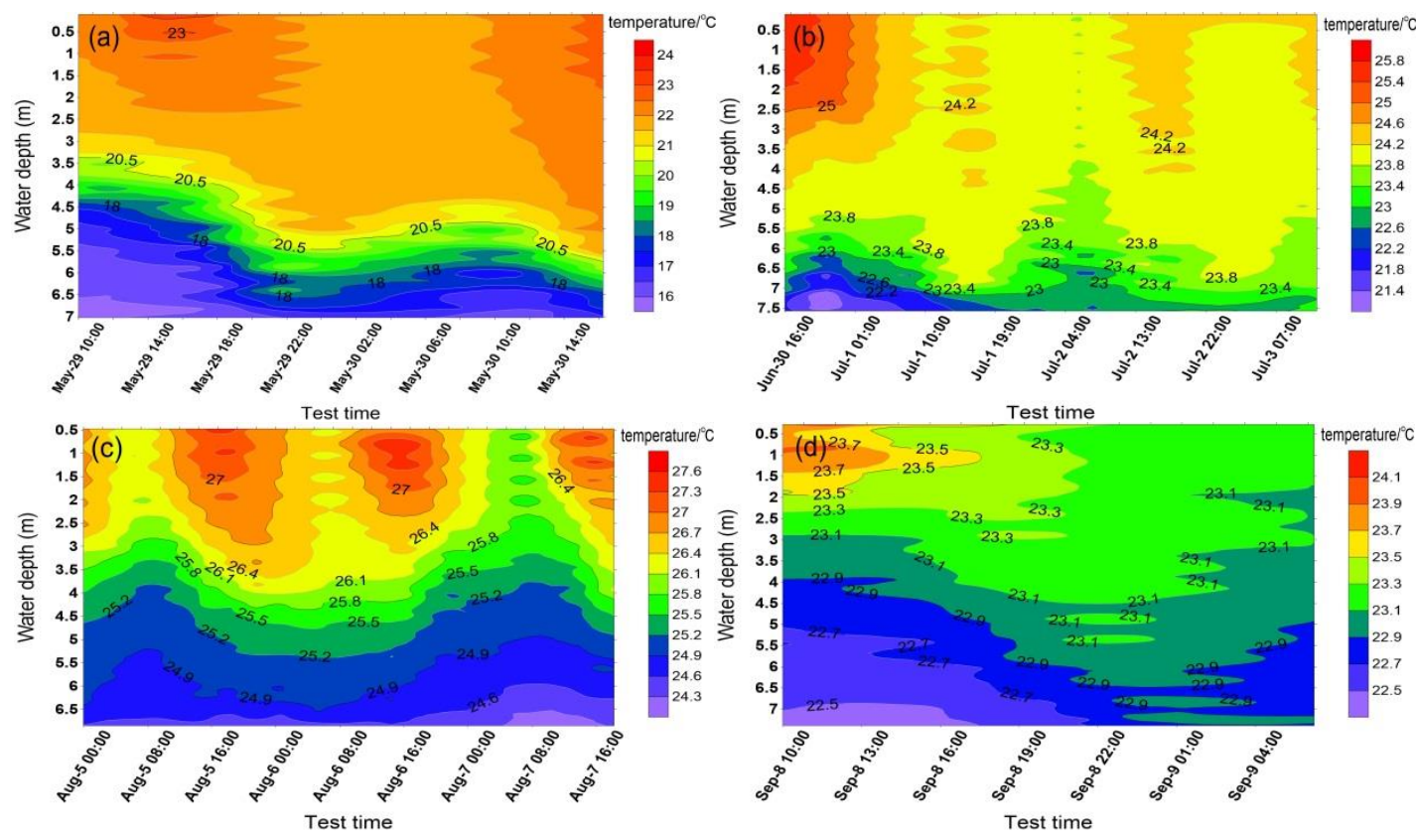

Figure 4. Interpolated contour maps of vertical water temperature for each test time

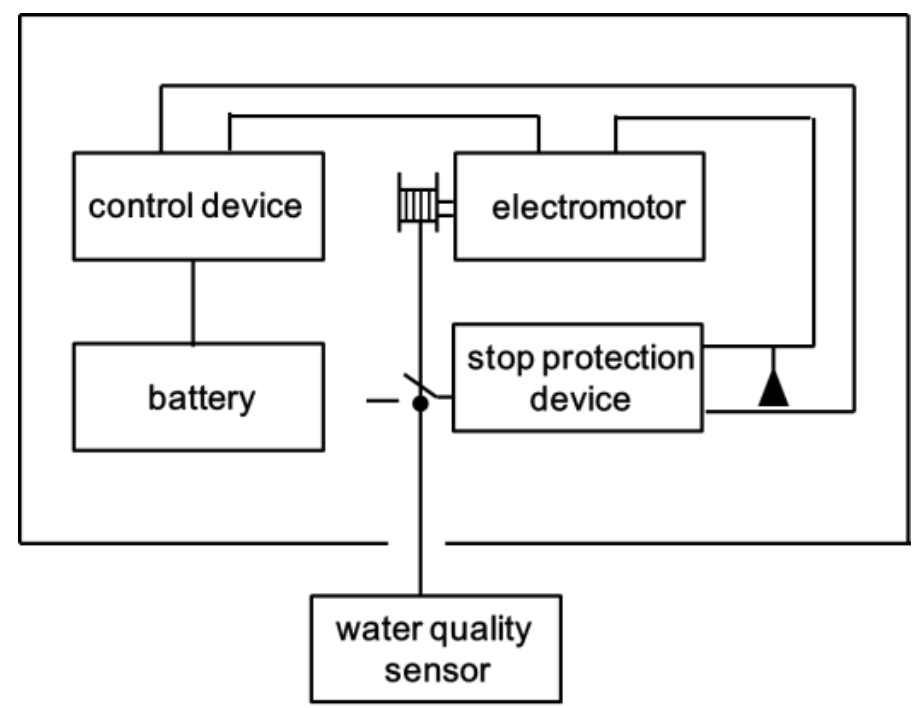

Figure 5. Schematic diagram of the self-designed lifting equipment 

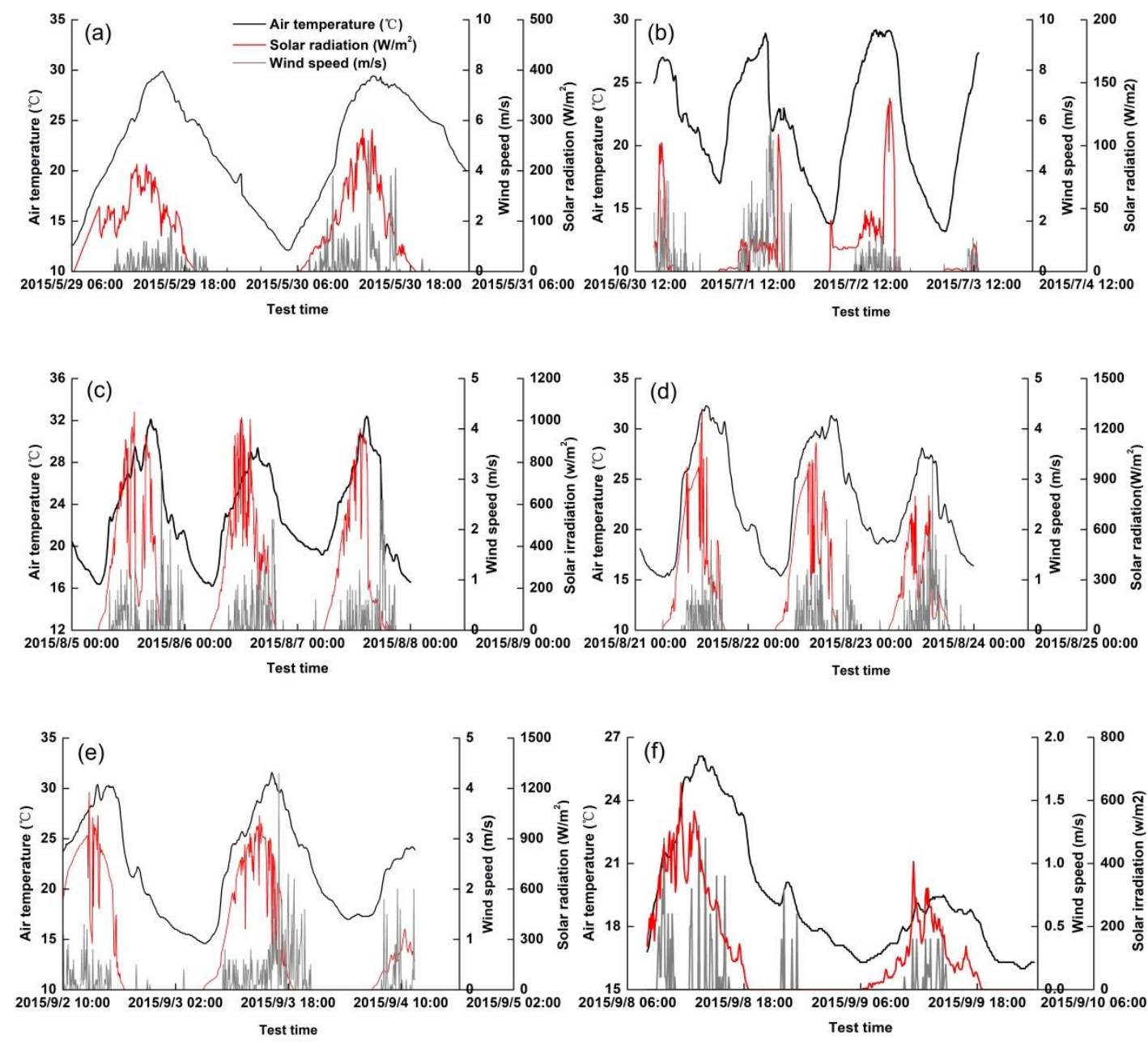

Figure 6. Meteorological data sequences for each test time including four times for vertical sampling $(a, b, c$ and $f)$ and two times ( $d$ and $e)$ for surface water sampling

During investigation of vertical Chl-a, air temperature and average water temperature varied by only $0.6^{\circ} \mathrm{C}$ in May, while they varied by up to $3.7^{\circ} \mathrm{C}$ in August (Table 1). On the contrary, the difference in water temperature between the epilimnion and hypolimnion was much higher in May than August and September (Fig. 4a). These findings indicate that the reservoir was in the primary stages of thermal stratification in May and well stratified in August. However, because of the rain and higher discharge at the dam (Table 1), the stratifications broke down from 1/July (Fig. 4b). The reservoir outlet discharge at both test times (Table 1) is within the range of reservoir withdrawals $\left(0.26-20.7 \mathrm{~m}^{3} / \mathrm{s}\right)$ during 2008 . Besides, stratifications were temporary in the daytime, while the water column underwent mixing at night time (Fig. $4 c$ and $d$ ). The depth of the mixing zone during night was smaller in August than in other surveys, indicating great water column stability in August. Taken together, these findings indicate that solar radiation increased water temperature, which drove thermal stratification and shoals the mixed layer.

Based on the criteria defined by Nürnberg (1996), Guanting Reservoir is a mesotrophic system. As shown in Figure 7, relatively low TP concentrations $(<0.1$ 
$\mathrm{mg} / \mathrm{l}$ ) were observed throughout the study period, and there were no significant differences in the TP and TN concentrations among water samples. All TN: TP ratios were greater than 16 , which is regarded as the optimum ratio for phytoplankton growth (OECD, 2006).

Table 1. Mean and variation range of physical variables in Guanting Reservoir during each test time

\begin{tabular}{|c|c|c|c|c|c|c|}
\hline Variables & 29/May-30/May & 30/Jun-3/Jul & 5/Aug-8/Aug & 21/Aug-23/Aug & 2/Sep-4/Sep & 8/Sep-9/Sep \\
\hline $\begin{array}{c}\text { Air temperature } \\
\left({ }^{\circ} \mathrm{C}\right)\end{array}$ & $\begin{array}{c}21.1 \\
(12.1-29.9)^{*}\end{array}$ & $\begin{array}{c}21.6 \\
(13.2-29.1)\end{array}$ & $\begin{array}{c}22.9 \\
(16.2-32.4)\end{array}$ & $\begin{array}{c}22.6 \\
(15.3-32.3)\end{array}$ & $\begin{array}{c}22.2 \\
(14.6-31.6)\end{array}$ & $\begin{array}{c}19.3 \\
(16-26.1)\end{array}$ \\
\hline $\begin{array}{l}\text { Solar radiation } \\
\left(\mathrm{W} / \mathrm{m}^{2}\right)\end{array}$ & $\begin{array}{c}55.7 \\
(0-282.7) \\
\end{array}$ & $\begin{array}{c}14.3 \\
(0-137.8) \\
\end{array}$ & $\begin{array}{c}227 \\
(0-1041.1) \\
\end{array}$ & $\begin{array}{c}225 \\
(0-1320) \\
\end{array}$ & $\begin{array}{c}258 \\
(0-1177) \\
\end{array}$ & $\begin{array}{c}112 \\
(0-665) \\
\end{array}$ \\
\hline Wind speed $(\mathrm{m} / \mathrm{s})$ & $\begin{array}{c}0.2 \\
(0-5.2) \\
\end{array}$ & $\begin{array}{c}0.32 \\
(0-6.1) \\
\end{array}$ & $\begin{array}{c}0.17 \\
(0-3.5)\end{array}$ & $\begin{array}{c}0.15 \\
(0-3.4) \\
\end{array}$ & $\begin{array}{c}0.18 \\
(0-4.3) \\
\end{array}$ & $\begin{array}{c}0.05 \\
(0-1.3) \\
\end{array}$ \\
\hline $\begin{array}{c}\text { Chl-a } \\
\text { concentration } \\
(\mu \mathrm{g} / \mathrm{l})\end{array}$ & $\begin{array}{c}9.8 \\
(3.3-15.6)\end{array}$ & $\begin{array}{c}6.7 \\
(3.4-12.5)\end{array}$ & $\begin{array}{c}7.6 \\
(3.5-12.3)\end{array}$ & $\begin{array}{c}6.8 \\
(3.4-10.11)\end{array}$ & $\begin{array}{c}5.1 \\
(2.6-9.0)\end{array}$ & $\begin{array}{c}7.0 \\
(3.3-10.1)\end{array}$ \\
\hline $\begin{array}{c}\text { Coefficient of } \\
\text { variation of Chl-a }\end{array}$ & 0.31 & 0.26 & 0.22 & 0.23 & 0.25 & 0.17 \\
\hline $\begin{array}{c}\text { Water } \\
\text { temperature }\left({ }^{\circ} \mathrm{C}\right)\end{array}$ & $\begin{array}{c}20.5 \\
(15.9-23.9) \\
\end{array}$ & $\begin{array}{c}23.9 \\
(18.0-25.9) \\
\end{array}$ & $\begin{array}{c}26.4 \\
(23.8-28.0) \\
\end{array}$ & $\begin{array}{c}26.3 \\
(25.6-27.1) \\
\end{array}$ & $\begin{array}{c}24.8 \\
(23.9-27.1) \\
\end{array}$ & $\begin{array}{c}23.2 \\
(22.1-24.3) \\
\end{array}$ \\
\hline Turbidity (FTU) & $\begin{array}{c}3.7 \\
(2.5-12.6)\end{array}$ & $\begin{array}{c}3.6 \\
(2.7-9.8)\end{array}$ & $\begin{array}{c}4.6 \\
(2.7-10.2)\end{array}$ & $\begin{array}{c}4.3 \\
(3.6-6.6)\end{array}$ & $\begin{array}{c}3.9 \\
(3.1-6.1)\end{array}$ & $\begin{array}{c}4.7 \\
(3.2-6.7)\end{array}$ \\
\hline $\begin{array}{c}\text { Average } \\
\text { discharge of the } \\
\text { dam }\left(\mathrm{m}^{3} / \mathrm{s}\right)\end{array}$ & 0.971 & 6.721 & 0.885 & 1.285 & 2.13 & 1.51 \\
\hline
\end{tabular}

*Brackets are corresponding to the range of measurements and displayed values are averages

In general, temporal variations in Chl-a concentrations varied slightly from May to September (Table 1); however, a general decrease in monthly Chl-a concentration was observed (Fig. 8a). Furthermore, the variations in Chl-a concentrations corresponded to differences in water temperature between the epilimnion and hypolimnion (Fig. $8 b$ ). Our results indicate that thermal stratification and mixing may limit phytoplankton growth vertically. Furthermore, a lower coefficient of variation (CV) of Chl-a vertical distribution was shown in August and September, when the reservoir was well stratified (Table 1).

In the four Chl-a vertical distribution investigations, the vertical profile of Chl-a concentration varied significantly between daytime and nighttime (Fig. 3). In May, the vertical profile of the Chl-a concentration primarily peaked around $3 \mathrm{~m}$ during daytime, with a maximum Chl-a concentration layer for thickness of $1.5 \mathrm{~m}$ (Fig. 3a). The maximum Chl-a concentration in the water column was about 1.5 times that in the surface water, whereas the depth of this layer changed with time and decreased to $7 \mathrm{~m}$ at night (Fig. 3a). At the same time, the surface Chl-a concentration increased at night. The surface Chl-a distribution recovered until sunset on the second day. However, this was not the case for the July survey. Specifically, the water column mixed from $1 / \mathrm{Jul}$, at which time the Chl-a concentration was homogenous during the day and night (Fig. 3b). The reservoir was well stratified in August, when there was a shallow-surface mixing layer at the top of the water column (Fig. 3c) and there was a similar vertical profile of Chl-a concentration in the daytime as in May. However, the maximum Chl-a 
concentration layer decreased slightly to $4 \mathrm{~m}$ at night (Fig. 3c). Therefore, the vertical profile of Chl-a was more stable through August. The Chl-a concentration showed a maximum concentration at around $1.5 \mathrm{~m}$ in the daytime on $8 /$ September. Because of water mixing at night, the maximum Chl-a concentration layer decreased and its thickness increased to $5.5 \mathrm{~m}$ (Fig. 3d). The linear regression between the maximum Chl-a concentration and the thermocline for all test times is significant $\left(\mathrm{R}^{2}=0.871\right.$, $\mathrm{P}<0.001)$. Specifically, although the position of the maximum Chl-a concentration layer varied temporally over the entire water column, it generally followed the same dynamics as the thermocline (Figs. 3 and 4).

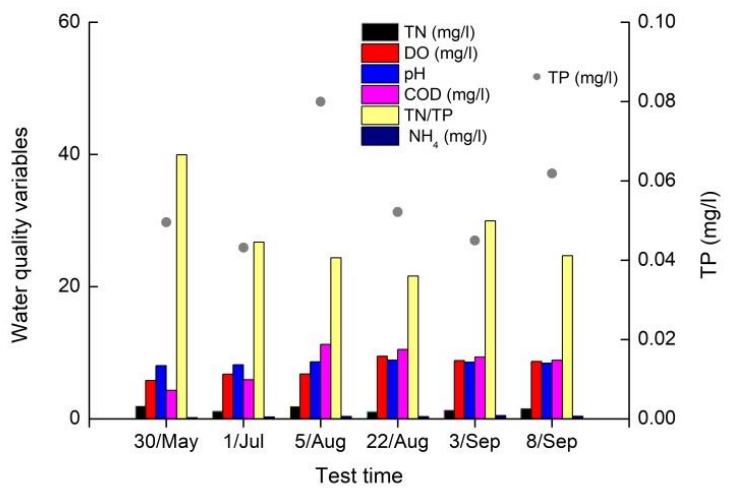

Figure 7. Water quality variables collected from a depth of $2 m$ at noon at $S 1$ on each sampling day
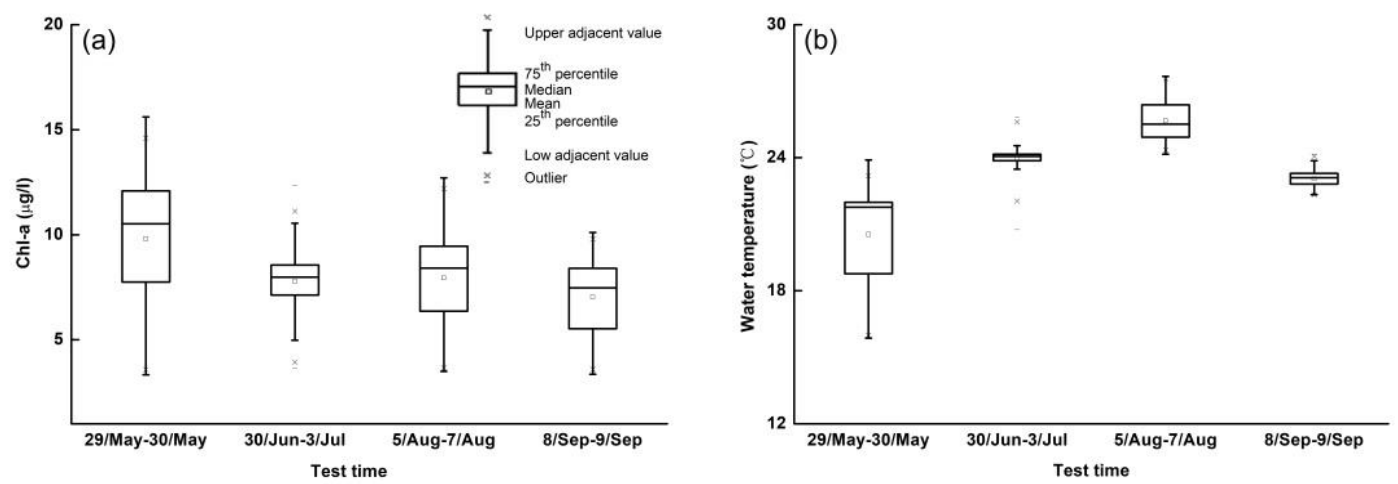

Figure 8. Box plots of vertical Chl-a concentration (a) and water temperature (b) at S1 for each test time

With the exception of July, the surface Chl-a concentration was inversely proportional to water temperature (Fig. $9 b$ ). Surface water temperature decreased during the rainfall events on $9 / \mathrm{Sep}$ and $1 / \mathrm{July}$ (Fig. $9 b$ and $f$ ). With the exception of the rainy days, surface Chl-a showed a clearly diurnal variation in which concentration increased at night and decreased during the day (Fig. $9 a$ and $c$ ). It is clear that the surface water temperature was correlated with Chl-a after an approximately 5-hour time lag, particularly in the August and September surveys (Fig. 9d and e). These findings suggest that phytoplankton took several hours to respond to the water temperature in the 
surface water column. Pearson's correlation analysis was calculated directly from the raw surface Chl-a data and environmental variables (Table 2), which indicated that Chla was significantly negatively correlated with meteorological variables and water temperature for each test time and all data (all $\mathrm{P}$ values $<0.01$ ), except for wind speed and Chl-a on 8/Sep and 9/Sep (P > 0.05). However, when the 5-hour time lag was considered, the Chl-a values generally became significantly positively correlated with meteorological variables and water temperature (all $\mathrm{P}$ values $<0.01$ ), except for results of May and 8/Sep (Table 2).
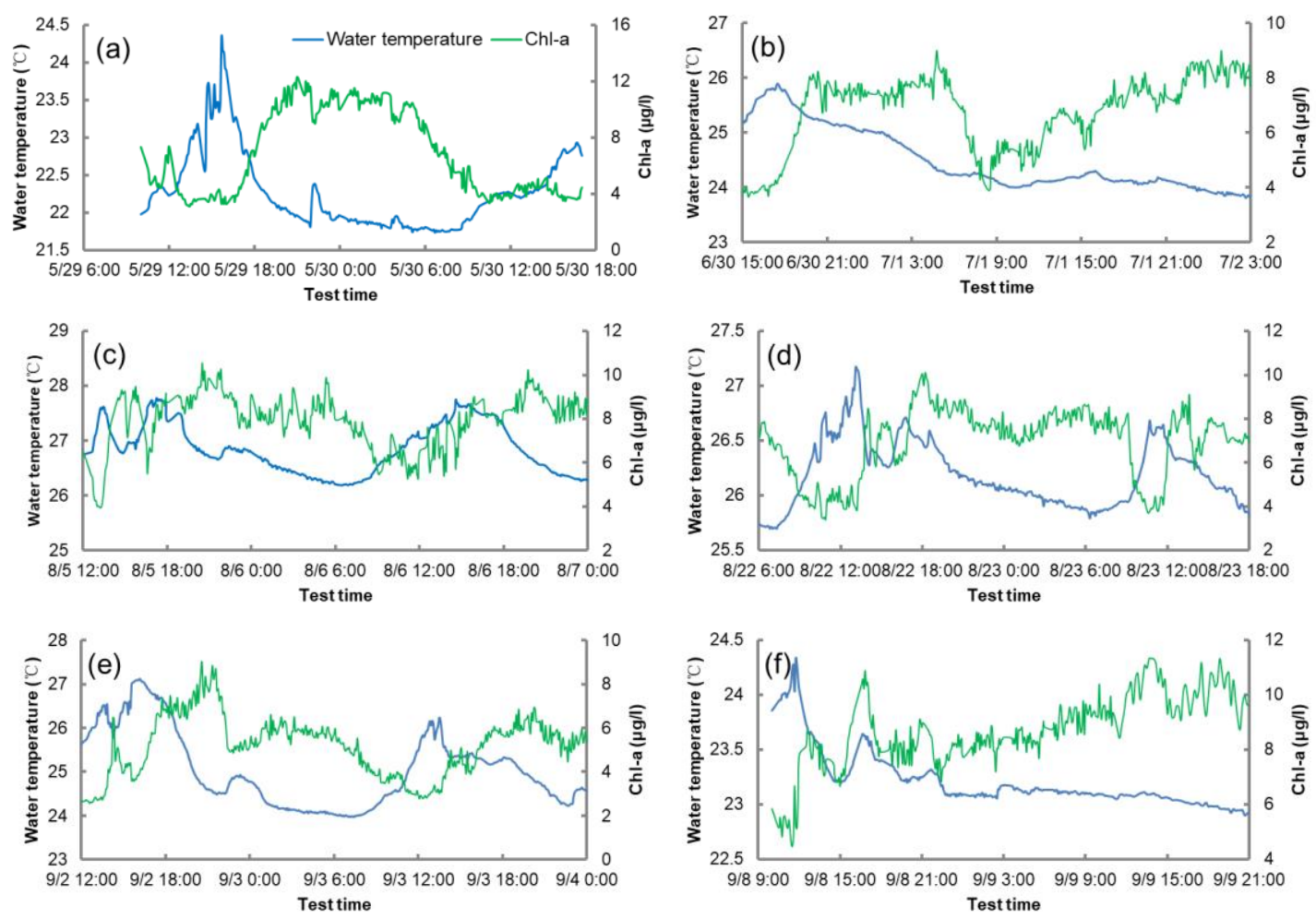

Figure 9. Variations in surface Chl-a concentration and surface water temperature during each test time

To identify the relationship between surface Chl-a and other environment variables, PCA was applied to daily Chl-a and water temperature, turbidity, discharge and meteorological data. Figure 10 shows the biplot ordination of samples and environment variables. The biplot ordination explains $78.3 \%$ of this variation and exhibits welldefined spatial patterns. The first ordination $(42.5 \%)$ was determined by most of the variables, particularly water temperature. Moreover, solar radiation and air temperature were on the positive side of the chart, while discharge and turbidity were on the negative side. The second ordination (35.8\%) was positively related to wind speed, whereas it was inversely correlated with Chl-a. The relationship on the Y-axis likely illustrates the negative effects of wind speed, solar radiation and air temperature on daily average Chl-a concentration. Additionally, discharge and turbidity contributed slightly to Chl-a concentration. Hence, the results of PCA are generally in accordance with the correlation results of raw data describing surface $\mathrm{Chl}-\mathrm{a}$ and meteorological variables. 
Table 2. Pearson correlation coefficients between surface Chl-a concentration and environmental variables, both raw data and 5-hour lag time of Chl-a concentration were considered

\begin{tabular}{c|c|c|c|c|c}
\hline Test time & & Air temperature & Solar radiation & Wind speed & Water temperature \\
\hline 29/May-30/May & Raw data & $-0.685^{* *}$ & $-0.818^{* *}$ & $-0.290^{* *}$ & $-0.638^{* *}$ \\
$(\mathrm{~N}=303)$ & Time lag & $0.400^{* *}$ & $-0.226^{* *}$ & -0.037 & $0.406^{* *}$ \\
\hline 30/Jun-3/Jul & Raw data & $-0.462^{* *}$ & $-0.231^{* *}$ & $-0.091^{* *}$ & $-0.139^{* *}$ \\
$(\mathrm{~N}=828)$ & Time lag & $0.453^{* *}$ & $0.158^{* *}$ & $0.177^{* *}$ & $0.178^{* *}$ \\
\hline 5/Aug-8/Aug & Raw data & $-0.308^{* *}$ & $-0.188^{* *}$ & $-0.596^{* *}$ & $-0.101^{* *}$ \\
(N = 793) & Time lag & $0.428^{* *}$ & $0.202^{* *}$ & $0.185^{* *}$ & $0.369^{* *}$ \\
\hline 21/Aug-23/Aug & Raw data & $-0.450^{* *}$ & $-0.771^{* *}$ & $-0.228^{* *}$ & $-0.533^{* *}$ \\
$(\mathrm{~N}=590)$ & Time lag & $0.490^{* *}$ & $0.234^{* *}$ & $0.127^{* *}$ & $0.485^{* *}$ \\
\hline 2/Sep-4/Sep & Raw data & $-0.375^{* *}$ & $-0.755^{* *}$ & $-0.135^{* *}$ & $-0.265^{* *}$ \\
$(\mathrm{~N}=576)$ & Time lag & $0.595^{* *}$ & $0.376^{* *}$ & $0.130^{* *}$ & $0.699^{* *}$ \\
\hline 8/Sep-9/Sep & Raw data & $-0.419^{* *}$ & $-0.398^{* *}$ & -0.092 & $-0.640^{* *}$ \\
$(\mathrm{~N}=315)$ & Time lag & $-0.398^{*}$ & 0.026 & 0.042 & $-0.373^{*}$ \\
\hline All data & Raw data & $-0.318^{* *}$ & $-0.118^{* *}$ & $-0.365^{* *}$ & $-0.095^{* *}$ \\
$(\mathrm{~N}=3405)$ & Time lag & $0.298^{* *}$ & $0.076^{* *}$ & $0.055^{* *}$ & $0.076^{* *}$ \\
\hline
\end{tabular}

$* *$ Significance at $99 \%$ confidence level

*Significance at $95 \%$ confidence level

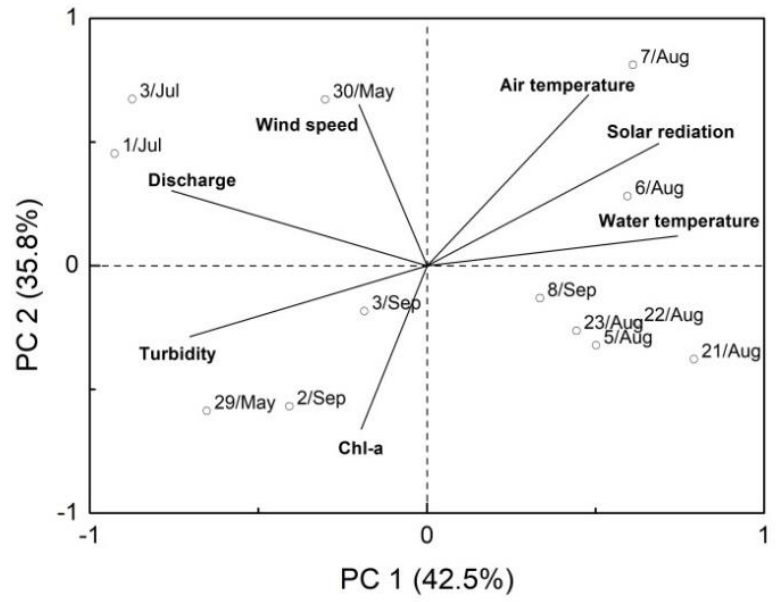

Figure 10. Principal component analysis ordination biplot. $($ Dots $=$ samples, arrows $=$ variables)

\section{Discussion}

The Chl-a concentrations observed from May to September showed a slight degree of variability from 2.6 to $15.6 \mu \mathrm{g} / \mathrm{l}$ (Table 1), which was within the range of Chl-a values (about 2.5-20 $\mu \mathrm{g} / \mathrm{l}$ ) reported in an earlier study conducted in Guanting Reservoir from June to December (He et al., 2011). It is well known that the lower CV values of vertical distributions are calculated when relatively higher wind speeds occur ( $\mathrm{Wu}$ and Kong, 2009). However, our results showed a lower CV of the Chl-a value appeared in August, when the reservoir was well stratified and there was great water column 
stability. Several previous studies have reported that reservoir trophic state is controlled by metrological factors and stratification pattern (Wu et al., 2014; Bresciani et al., 2013; León et al., 2016). Generally, a decrease in monthly Chl-a concentration was shown for the four vertical Chl-a measurements in summer. Smaller variations in Chl-a concentration were in accordance with the smaller difference in water temperature between the epilimnion and hypolimnion. When lower water temperature difference existed in the water column, the phytoplankton tended to be homogenous, and therefore leaded to less variation of Chl-a concentration (Lopes et al., 2005; Serra et al., 2007).

It is well known that phytoplankton in lakes and reservoirs are recognized as limited by TP if the TN: TP ratio is relatively large, while they are limited by TN if the ratio is relatively small (Wang et al., 2008). These findings suggest that phytoplankton at both test times in Guanting Reservoir were probably limited by TP. Because of the limited water quality samples, the relationship between water quality parameters was not examined. The TP concentrations varied slightly at both test times (Fig. 7). It is likely the main reason to induce less difference of mean Chl-a concentration for each test time. In general, Chl-a concentration was significantly correlated with TP concentration (Zhou et al., 2016). Hence, the smaller Chl-a concentration observed in September was likely because of the lower TP (Fig. 7). According to Deng et al. (2012), a temperature range of $21-29^{\circ} \mathrm{C}$ is suitable for phytoplankton growth. The TP concentration peak in August was likely the result of stronger activity of P-decomposing bacteria at higher temperature (Cui et al., 2005). However, the Chl-a in August was lower than that in May (Fig. 8a). Wu et al. (2014) reported that the effects of nutrients on Chl-a were not obvious. Therefore, seasonal variations in Chl-a during summer were not caused by the TP concentration and water temperature. In fact, highest light were observed in August (Fig. 6c), similar results were reported by Edwards et al. (2016), who confirmed that very strong light could restrain phytoplankton growth. Light might be a limiting factor when the euphotic zone is much smaller than the mixing zone (Kalff, 2002; Becker et al., 2010). The lowest solar radiation was recorded in July, indicating that it controlled phytoplankton growth (Fig. 6b). In addition, flow condition was inversely proportional to algal level in the short term (Kim et al., 2014), and the high discharge of the dam suggests that Chl-a may have been diluted during rainy days (Table 1).

Our investigations provide a broader understanding of short-term Chl-a vertical distribution within consecutive days. In both surveys, the lowest Chl-a appeared at the bottom of the water column, which is consistent with the findings of a previous study (Wu and Kong, 2009). Water temperature was the environmental variable that best explained vertical distributions of the phytoplankton community (Lopes et al., 2005). Variations in the position of the maximum Chl-a concentration layer between days generally followed the same dynamics as thermoclines, which is in accordance with the results reported by Serra et al. (2007). The Chl-a vertical distribution showed different behavior at each test time. Because of continuous mixing during the day and night in early July, Chl-a was likely directly influenced by rain and higher discharge. When the reservoir was primarily stratified in May (Fig. 4a), the developing thermocline was shallow and the epilimnion was easily mixed by winds and night-time convection, which tended to homogenize the vertical distribution of phytoplankton (Cyr, 2017). In contrast, stratification may decouple vertical circulation and mixing at night (Marcé et al., 2006). Guanting Reservoir was well stratified in August; therefore, the maximum Chl-a concentration layer was relatively stable at around $3 \mathrm{~m}$ during both the day and night. In September, the maximum concentration was located at the epilimnion during 
the day, similar to the vertical distribution of phytoplankton suggested by Serra et al. (2007), who investigated phytoplankton that accumulated close to the surface during calm periods in September.

In the present study, stratifications were temporary and the maximum Chl-a concentration layer varied with downwelling at night. Wind speed (Cao et al., 2006), wind direction (Serra et al., 2007) and wind time (Cyr, 2017) play important roles in regulation of daily phytoplankton vertical downwelling (Cardoso and Motta-Marques, 2009) and horizontal movement (He et al., 2011). Minor stratifications can be easily broken down by wind ( $\mathrm{Li}$ et al., 2007), and relatively strong winds of above $5 \mathrm{~m} / \mathrm{s}$ directly induce vertical mixing and disturbance in the water column (Antenucci and Imerito, 2000). A few periods in which there were strong winds were recorded in our results. In particular, the test site is located near the south boundary of the entire reservoir, while on windy days (30/May and 1/July) the predominant wind direction was from the northwest and north, respectively. These results are similar to those reported by Cyr (2017), who suggested that when the wind was small but continuous, wind stress pushes the surface water downwind, creating downward flow at the downwind end of the basin.

Additionally, the surface Chl-a concentration exhibited diurnal periodic variation. It is well known that night-time vertical circulation and mixing as well as sinking of phytoplankton was induced by wind (Wu and Kong, 2009; Bresciani et al., 2013), consequently, this would homogenize the phytoplankton and enhance surface Chl-a concentrations at night. When considering seasonal and interannual data during longterm surveys, the relationship between Chl-a and light (Phlips et al., 1995), ln (Chl-a) and average air temperature (Zhou et al., 2016) was positively correlated. Moreover, interannual decreasing wind speed led to longer cyanobacterial bloom durations (Zhang et al., 2012). However, in the present short-term investigation, the results of PCA suggested that the daily average Chl-a was negatively correlated with daily average meteorological factors and water temperature. Our results agree with those of previous studies that showed Chl-a was negatively correlated with water temperature and light (Felip and Catalan, 2000) and wind speed (Serra et al., 2007). Our results demonstrate raw surface Chl-a values generally change as a negative function of meteorological factors and water temperature. However, when surface Chl-a was considered based on a 5-hour lag time, the relationship generally became significantly positive. Pérez-Ruzafa et al. (2005) found a 1-week time lag between Chl-a and nutrients and Bresciani et al. (2013) demonstrated that the time lags between Chl-a and solar radiation, water temperature and wind speed were 3 hours, 8-9 hours and 5 days, respectively. Therefore, time lag is a known phenomenon in short-term investigations, and the fivehour time lag in our study suggests a very rapid response of Chl-a to meteorological factors and water temperature in Guanting Reservoir.

\section{Conclusions}

This study describes the monthly and diurnal variation in vertical and surface distribution of Chl-a, as well as elucidates the quantitative relationships between Chl-a, water temperature, nutrients, meteorological factors and other physical variables in Guanting Reservoir during summer. In general, monthly Chl-a concentration exhibited a decreasing trend. Moreover, thermal stratification and mixing were found to be of great importance in controlling variation in the maximum Chl-a concentration layer in the 
water column and variations in the position of the maximum Chl-a concentration layer between days generally followed the same dynamics as the thermocline. Furthermore, stratifications were temporary, with the maximum Chl-a concentration layer varying with downwelling and becoming homogenized at night because of wind driven mixing. The surface Chl-a concentration was also found to increase at night and decrease during the day, except on rainy days. The results of PCA and Pearson's correlation analysis indicated that the surface Chl-a concentration was significantly negatively correlated with air temperature, solar radiation, wind speed and water temperature. However, when a 5-hour time lag was considered, the relationships among surface Chl-a concentration, meteorological factors and water temperature became significantly positive.

Spatial and temporal variations in phytoplankton are always dynamic and highly variable, and more work is needed to assess the combined effects of environment variables on Chl-a concentration. Based on the species, size and buoyancy characteristics, further research will be devoted to hydrodynamics variables that drive phytoplankton communities spatially and temporally on a large scale.

Acknowledgements. This study was jointly supported by the National Key Research and Development Program of China (Grant Nos. 2016YFC0401308, 2018YFC0406502) and the National Natural Science Foundation of China (Grant Nos. 51779007, 41671018). We are grateful to the anonymous reviewers for their helpful suggestions, which have improved the quality of the manuscript.

\section{REFERENCES}

[1] APHA (American Public Health Association) (1998): Standard Methods for the Examination of Water and Waste Water. 20th ed. - American Public Health Association, Washington, DC.

[2] Antenucci, J., Imerito, A. (2000): The CWR Dynamic Reservoir Simulation Model DYRESM. Science Manual. - Centre for Water Research, The University of Western Australia, Perth.

[3] Becker, V., Caputo, L., Ordóñez, J., Marcé, R., Armengol, J., Crossetti, L. O., Huszar, V. L. M. (2010): Driving factors of the phytoplankton functional groups in a deep Mediterranean reservoir. - Water Research 44: 3345-3354.

[4] Beutler, M., Wiltshire, B., Meyer, C., Moldaenke, C., Luring, C., Meyerhofer, M., Hansen, U., Dau, H. (2002): A fluorometric method for the differentiation of algal populations in vivo and in situ. - Photosynthesis Research 72: 39-53.

[5] Bresciani, M., Rossini, M., Morabito, G., Matta, E., Pinardi, M., Cogliati, S., Julitta, T., Colombo, R., Braga, F., Giardino, C. (2013): Analysis of within-and between-day chlorophyll-a dynamics in Mantua Superior Lake, with a continuous spectroradiometric measurement. - Marine and Freshwater Research 64: 303-316.

[6] Cao, H. S., Kong, F. X., Luo, L. C., Shi, X. L., Zhou, Y., Zhang, X. F., Tao, Y. (2006): Effects of wind and wind-induced waves on vertical phytoplankton distribution and surface blooms of microcystis aeruginosa in Lake Taihu. - Journal of Freshwater Ecology 21: 231-238.

[7] Cardoso, L. S., Motta-Marques, D. M. L. (2009): Hydrodynamics-driven plankton community in a shallow lake. - Aquatic Ecology 43: 73-84.

[8] Chen, C., Zhang, Z., Ding, A., Wu, J., Xiao, J., Sun, Y. (2011): Bar-coded pyrosequencing reveals the bacterial community during microcystis, water bloom in Guanting Reservoir, Beijing. - Procedia Engineering 18: 341-346. 
[9] Cui, L. I., Yuan, H., Huang, H. (2005): Vertical distribution of phosphorus and Pdissolving/ decomposing bacteria in the sediment of Guanting reservoir. - Science in China Series D (Earth Sciences) 48: 285-294.

[10] Cyr, H. (2017): Winds and the distribution of nearshore phytoplankton in a stratified lake. - Water Research 122: 114-127.

[11] Dai, R., Liu, H., Qu, J., Ru, J., Hou, Y. (2008): Cyanobacteria and their toxins in Guanting Reservoir of Beijing, China. - Journal of Hazardous Materials 153: 470-477.

[12] Deng, Y., Tang, X., Huang, B., Ding, L. (2012): Effect of temperature and irradiance on the growth and reproduction of the green macroalga, Chaetomorpha valida (Cladophoraceae, Chlorophyta). - Journal of Applied Phycology 24: 927-933.

[13] Edwards, K. F., Thomas, M. K., Klausmeier, C. A., Litchman, E. (2016): Phytoplankton growth and the interaction of light and temperature: a synthesis at the species and community level. - Limnology Oceanography 61: 1232-1244.

[14] Felip, M., Catalan, J. (2000): The relationship between phytoplankton biovolume and chlorophyll in a deep oligotrophic lake: decoupling in their spatial and temporal maxima. - Journal of Plankton Research 22: 1987-97.

[15] He, G., Fang, H., Bai, S., Liu, X., Chen, M., Bai, J. (2011): Application of a threedimensional eutrophication model for the Beijing Guanting Reservoir, China. Ecological Modelling 222: 1491-1501.

[16] He, W., Chen, S., Liu, X., Chen, J. (2008): Water quality monitoring in a slightlypolluted inland water body through remote sensing. Case study of Guanting Reservoir in Beijing, China. - Frontiers of Environmental Science Engineering in China 2: 163-171.

[17] Kalff, J. (2002): Limnology: Inland Water Ecosystems. - Prentice Hall, New Jersey.

[18] Kim, D. W., Min, J. H., Yoo, M., Kang, M., Kim, K. (2014): Long-term effects of hydrometeorological and water quality conditions on algal dynamics in the Paldang dam watershed, Korea. - Water Science Technology Water Supply 14: 601-608.

[19] León, J. G., Beamud, S. G., Temporetti, P. F., Atencio, A. G., Diaz, M. M., Pedrozo, F. L. (2016): Stratification and residence time as factors controlling the seasonal variation and the vertical distribution of chlorophyll-a in a subtropical irrigation reservoir. International Review of Hydrobiology 101: 36-47.

[20] Li, T., Wang, D., Zhang, B., Liu, H., Tang, H. (2007): Morphological characterization of suspended particles under wind-induced disturbance in Taihu lake, China. Environmental Monitoring Assessment 127: 79-86.

[21] Li, Y., Zhang, Y., Shi, K., Zhou, Y., Zhang, Y., Liu, X. (2017): Spatiotemporal dynamics of chlorophyll-a, in a large reservoir as derived from Landsat 8 OLI data: understanding its driving and restrictive factors. - Environmental Science Pollution Research 25: 13591374.

[22] Lopes, M., Bicudo, C. E., Ferragut, M. C. (2005): Short term spatial and temporal variation of phytoplankton in a shallow tropical oligotrophic reservoir, southeast Brazil. Hydrobiologia 542: 235-247.

[23] Marcé, R., Moreno-Ostos, E., Ordóñez, J., Feijoó, C., Navarro, E., Caputo, L., Armengol, J. (2006): Nutrient fluxes through boundaries in the hypolimnion of Sau reservoir: Expected patterns and unanticipated processes. - Limnetica 25: 527-540.

[24] Neveux, J., Dupouy, C., Blanchot, J., Bouteiller, A. L., Landry, M. R., Brown, S. L. (2003): Diel dynamics of chlorophylls in high-nutrient, low-chlorophyll waters of the equatorial pacific $\left(180^{\circ}\right)$ : interactions of growth, grazing, physiological responses, and mixing. - Journal of Geophysical Research Oceans 108: 1-17.

[25] Nürnberg, G. K. (1996): Trophic state of clear and colored, soft and hardwater lakes with special consideration of nutrients, anoxia, phytoplankton and fish. - Lake Reservoir Management 12: 432-447.

[26] OECD (2006): Eutrophication of Waters. Monitoring, Assessment and Control. Research of the Organization for Economic Cooperation and Development (OECD). - Prepared by 
Soil Water Conservation Society of Metro Halifax (SWCSMH). http://lakes.chebucto.org/TPMODELS/OECD/oecd.html.

[27] Pérez-Ruzafa, A., Fernández, A. I., Marcos, C., Gilabert, J., Quispe, J. I., García-Charton, J. A. (2005): Spatial and temporal variations of hydrological conditions, nutrients and chlorophyll a, in a Mediterranean coastal lagoon (Mar Menor, Spain). - Hydrobiologia 550: 11-27.

[28] Phlips, E. J., Aldridge, F. J., Schelske, C. L., Crisman, T. L. (1995): Relationships between light availability, Chlorophyll a, and tripton in a large, shallow subtropical lake. - Limnology Oceanography 40: 416-421.

[29] Rigosi, A., Hanson, P., Hamilton, D. P., Hipsey, M., Rusak, J. A., Bois, J., Sparber, K., Chorus, I., Watkinson, A. J., Qin, B., Kim, B., Brookes, J. D. (2016): Determining the probability of cyanobacterial blooms: the application of Bayesian networks in multiple lake systems. - Ecological Applications A Publication of the Ecological Society of America 25: 186-199.

[30] Serra, T., Vidal, J., Casamitjana, X., Soler, M., Colomer, J. (2007): The role of surface vertical mixing in phytoplankton distribution in a stratified reservoir. - Limnology Oceanography 52: 620-634.

[31] Sun, Y. J., Chen, C., Ding, A. Z., Zhao, X. H., Zhang, H. C. (2015): The corresponding of microbial diversity on water quality and environmental variables of Guanting Reservoir. - China Environmental Science 35: 1547-1553 (in Chinese).

[32] Wu, X., Kong, F. (2009): Effects of light and wind speed on the vertical distribution of Microcystis aeruginosa colonies of different sizes during a summer bloom. - International Review of Hydrobiology 94: 258-266.

[33] Wu, Z., He, H., Cai, Y., Zhang, L., Chen, Y. (2014): Spatial distribution of chlorophyll-a and its relationship with the environment during summer in Lake Poyang: a Yangtzeconnected lake. - Hydrobiologia 732: 61-70.

[34] Wang, H. J., Liang, X. M., Jiang, P. H., Wang, J., Shi-Kai, W. U., Wang, H. Z. (2008): TN:TP ratio and planktivorous fish do not affect nutrient-chlorophyll relationships in shallow lakes. - Freshwater Biology 53: 935-944.

[35] Xie, J., Xu, R. (2014): Variation characteristics analysis of the diurnal and monthly meteorological elements at different stations in Beijing. - Meteorological and Environmental Sciences 37: 20-28 (in Chinese).

[36] Zhang, M., Duan, H., Shi, X., Yu, Y., Kong, F. (2012): Contributions of meteorology to the phenology of cyanobacterial blooms: implications for future climate change. - Water Research 46: 442-52.

[37] Zhou, Q., Zhang, Y., Lin, D., Shan, K., Luo, Y., Zhao, L., Tan, Z. W., Song, L. R. (2016): The relationships of meteorological factors and nutrient levels with phytoplankton biomass in a shallow eutrophic lake dominated by cyanobacteria, Lake Dianchi from 1991 to 2013. - Environmental Science Pollution Research International 23: $15616-15626$. 